\title{
Laparoscopic harvesting of rectus abdominis for repair of perineal defect in ELAPE, review of cases published
}

\author{
Kanapathi Rajaratnam* and Rishi Sen \\ Department of Colorectal Surgery, Bedford Hospital, UK
}

\begin{abstract}
Background: An extralevator abdominoperineal excision can leave a wide perineal wound. Such large wounds are prone to infection and perineal herniation, especially in patients undergoing long courses of chemo/radiotherapy. The choice of wound closure is a challenge to most surgeons. Different approaches to the perineal repair exist, varying from primary or mesh closure to myocutaneous flaps. Each technique has advantages, but also complications. Rectus abdominis muscle flaps are very successful in reducing complications of perineal wound breakdown and hernia formation, but they require an open large wound in the abdomen or laparotomy. We describe a laparoscopic surgical technique which achieves harvesting a rectus abdominis muscle flap for perineal closure while it avoids making a large abdominal laparotomy wound.
\end{abstract}

Method: After doing the laparoscopic dissection of the colon and rectum and division of the colon, the right rectus abdominis muscle flap is harvested with the vascular pedicle. At the end, a colostomy is formed. The patient is subsequently turned to prone position and an ExtraLevator AbdominoPerineal Excision (ELAPE) is performed. The flap is sutured to the edges of the levator ani to repair the defect and the skin is closed.

Conclusion: The minimal access laparoscopic method of harvesting the rectus muscle flap explained here is a novel, feasible and less morbid method to get a vascularised rectus muscle flap to fill the pelvis and to cover the perineal defect.

\section{Introduction}

Various techniques have been described for the closure or repair of the perineal wound after abdominoperineal resection (APR) for rectal cancer. These vary from primary closure to biological mesh closure. Primary closure has resulted in high rate of immediate wound break down and long term perineal hernia formation, especially in patients receiving long courses of chemo/radiotherapy [1]. The exact incidence of development of perineal hernia following APR/Extra Levator Abdominoperineal Excision (ELAPE) may be higher because of underreporting.

With the improved oncological outcome after ELAPE, the resulting defect in the perineum requires a different method of reconstruction than a simple closure consisting of perineal muscle approximation and skin closure. Various approaches are available to close this defect primarily. The methods presently practiced are Rectus Abdominis muscle flap (RAM flap) [2,3], gluteal flap (with a perforator) [4], Gracillic flap and repair with biological or synthetic mesh (nonabsorbable/absorbable). Each method has its own advantages and disadvantages [5].

The advantages of RAM flap include not only that it covers the defect in the pelvic diaphragm, but also it fills the pelvic cavity. This reduces the chances of small bowel hernia and adhesion within the pelvis, which is one of the causes for small bowel obstruction during the post-operative period. However, the open method of harvesting the RAM flap transforms the minimal access operation to a large open laparotomy wound (i.e. it takes away all the advantages of minimal access surgery).

Improvements in colorectal surgical techniques through minimal access surgery such as laparoscopic or Robotic ELAPE leave the patient only with the perineal and few port site wounds. Although the use of biologic/synthetic mesh for the repair of the perineal defect sounds a very attractive with minimal-access approach [6,7], it has its own deficiencies, such as wound break down, mesh infection, seroma formation, small bowel adhesion, erosion of the bowel in the case of synthetic mesh and perineal hernia formation in long term. Repairing the defect with the flaps from gluteal area or from the thigh carry its own morbidities from the donor sites and post-operative additional pain $[6,8]$.

We describe a minimal access approach method, by which the empty pelvic cavity and the defect in the perineum resulting from the excision of rectum, mesorectum and anus will be filled with rectus muscle with good blood supply to repair the defect.

\section{Surgical technique/method}

After the laparoscopic dissection and the division of the colon at the proximal end for the end-colostomy, the right rectus abdominis muscle is divided transversely at the level above the umbilicus laparoscopically with the peritoneum and posterior rectus sheath leaving the anterior sheath intact. The right rectus muscle is preferred over the left to avoid interference with the end colostomy on the left side. This may not be an appropriate method for a double stoma in the case of ileal conduit

Correspondence to: Kanapathi Rajaratnam, Department of Colorectal Surgery, Bedford Hospital, UK, Tel: 00447944971017, E-mail: nmkrratnam@yahoo.com

Key words: extra levator abdomino perineal Excision, rectus abdominis muscle flap, laparoscopy, perineal closure

Received: February 21, 2018; Accepted: March 05, 2018; Published: March 08 2018 


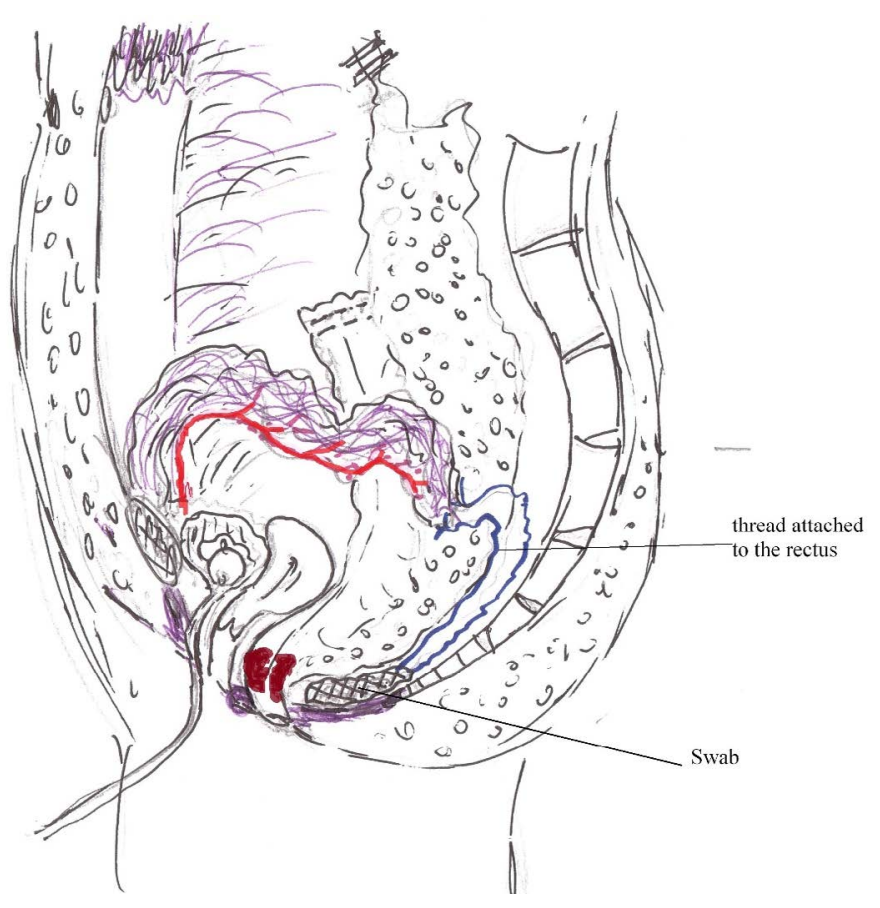

Figure 1. Figure showing harvesting of the flap.

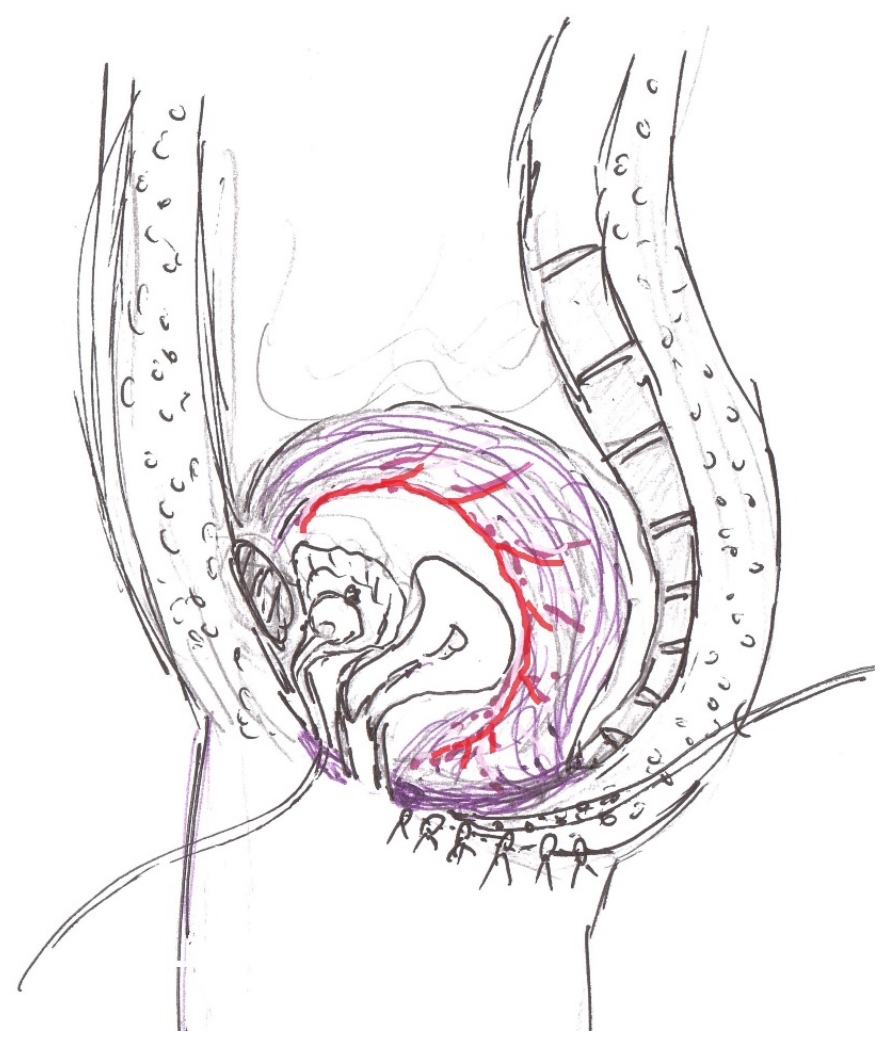

Figure 2. Figure showing the repair with the flap.

and end colostomy in case of pelvic eventration. An additional port for the laparoscope along the left mid clavicular line at an appropriate level may be needed for good visualisation of the right rectus muscle flap dissection. A $30^{\circ}$ laparoscope or flexi tip scope will be suitable for this technique to have a good visualisation of the abdominal wall. Ultrasonic energy devices would be most appropriate to divide the muscle and the right superior epigastric vessel. Then the rectus muscle is carefully mobilised laparoscopically with the peritoneum and the posterior sheath separating it vertically along the linea semilunaris and the linea alba. The inferior epigastric artery is best preserved with the posterior rectus sheath and the transversals fascia below the arcuate line. Care should be taken when dissecting the lateral border of the rectus abdominis muscle at the lower end not to damage the inferior epigastric vessel at its entry into the rectus. Mobilisation will be done up to the symphysis leaving the anterior sheath intact throughout. Leaving the anterior sheath intact will obviate the development of ventral hernia.

Subsequently, the divided superior edge of the rectus muscle is sutured to a swab with a long thread which is inserted into the posterior lowermost end of the TME plane as a marker behind the dissected rectum to facilitate easy retrieval of the flap when the patient is turned prone for perineal dissection and reconstruction.

After this the stoma is formed, the port sites are closed, and the patient is turned to the prone position for perineal dissection.

The ELAPE is continued from the perineum to complete the rectal excision. The swab maker would be retrieved from the perineal wound. The suture connected to the flap kept loosely attached to haemostat until the whole dissection is over. Once the dissection is over the rectus flap is guided out towards the wound with the help of the attached thread. The viability of the flap would be checked. Then the muscle flap is sutured to the edges of the origin of the levator ani completing the repair of the perineal defect. The subcutaneous tissue and the skin are closed. In most of the patients skin defect is not an issue in closure. If any tension in the skin is encountered, lateral mobilization of the skin could help with approximation. A small suction drain is left between the flap and the subcutaneous tissue. The skin is closed with vertical mattress sutures with non-absorbable threads.

A review of the literature has shown a few cases of rectus muscle flap harvesting through a minimal-access approach. Agochukwu et al have published three cases of similar harvesting of rectus muscle for perineal reconstruction [9]. Ibrahim et al, [10] have explained the robotic harvesting method of rectus muscle for various purposes.

\section{Conclusion}

This novel technique of harvesting the right rectus abdominis muscle flap laparoscopically with posterior sheath for repairing the defect in the pelvic diaphragm is very feasible and less morbid method. It is done completely by the laparoscopic method. It avoids large incision in the abdomen, enhances healing at the perineum and reduces the chances of small bowel adhesion in the deep pelvis. One drawback could be faced in ascertaining the viability of the flap during the post-operative period as it is covered by the skin at the perineal site. Another problem may be encountered in maintaining the orientation of the flap correctly without getting it twisted or rotated when it is delivered through the perineal defect.

\section{Conflicts of interest}

Authors declared that they have no conflicts of interest to disclose.

\section{References}

1. Musters GD, Buskens CJ, Bemelman WA, Tanis PJ (2014) Perineal wound healing after abdominoperineal resection for rectal cancer: a systematic review and metaanalysis. Dis Colon Rectum 57: 1129-1139. [Crossref]

2. Bell SW, Dehni N, Chaouat M, Lifante JC, Parc R, et al. (2005) Primary rectus abdominis myocutaneous flap for repair of perineal and vaginal defects after extended abdominoperineal resection. Br J Surg 92: 482-486. [Crossref] 
3. Taylor GI, Corlett R, Boyd JB (1983) The extended deep inferior epigastric flap: a clinical technique. Plast Reconstr Surg 72: 751-765. [Crossref]

4. Hainsworth A, Al Akash M, Roblin P, Mohanna P, Ross D, et al. (2012) Perineal reconstruction after abdominoperineal excision using inferior gluteal artery perforator flaps. Br J Surg 99: 584-588. [Crossref]

5. Foster JD, Pathak S, Smart NJ, Branagan G, Longman RJ, et al. (2012) Reconstruction of the perineum following extralevator abdominoperineal excision for carcinoma of the lower rectum: a systematic review. Colorectal Dis 14: 1052-1059. [Crossref]

6. Musters GD, Lapid O, Stoker J, Musters BF, Bemelman WA, et al. (2016) Is there a place for a biological mesh in perineal hernia repair? Hernia 20: 747-754. [Crossref]
7. Schiltz B, Buchs NC, Penna M, Scarpa CR, Liot E, et al. (2017) Biological mesh reconstruction of the pelvic floor following abdominoperineal excision for cancer: A review. World J Clin Oncol 8: 249-254. [Crossref]

8. Narang SK, Alam NN, Köckerling F, Daniels IR, Smart NJ (2016) Repair of Perineal Hernia Following Abdominoperineal Excision with Biological Mesh: A Systematic Review. Front Surg 3: 49. [Crossref]

9. Agochukwu N, Bonaroti A, Beck S, Liau J (2017) Laparoscopic Harvest of the rectu Abdominis for Perineal Reconstruction. Plast Reconstr Surg Glob Open 5: e1581. [Crossref]

10. Ibrahim AE, Sarhane KA, Pederson JC, Selber JC (2014) Robotic harvest of the rectus abdominis muscle: principles and clinical applications. Semin Plast Surg 28: 26-31. [Crossref]

Copyright: @2018 Rajaratnam K. This is an open-access article distributed under the terms of the Creative Commons Attribution License, which permits unrestricted use, distribution, and reproduction in any medium, provided the original author and source are credited. 